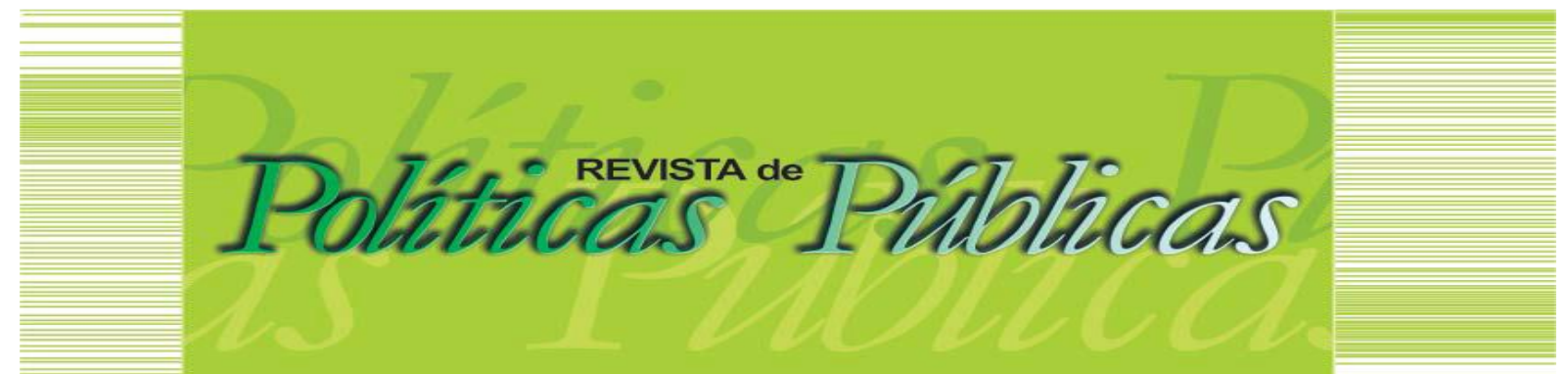

\title{
A VIOLÊNCIA CONTRA AS MULHERES NO BRASIL: uma análise feminista, antirracista e anticapitalista
}

\author{
Renata Gomes da Costa ${ }^{1}$ \\ Mariana Teixeira da Paz ${ }^{2}$ \\ Carolina Rubano de Oliveira ${ }^{3}$
}

\begin{abstract}
Resumo
O presente artigo analisa alguns dos resultados do projeto de pesquisa "Os fundamentos da violência contra as mulheres no Brasil", que investiga a origem e a estrutura deste fenômeno, com base em uma análise documental no "Atlas da Violência 2020",no "Anuário de Segurança Pública 2020" e no documento "Estatísticas de gênero indicadores sociais das mulheres no Brasil (IBGE-2018)", para coletar dados referentes às situações de violência contra as mulheres.Após essa sistematização, faz uma revisão da literatura empírica, ou seja, reinterpreta os dados a partir de um debate teórico que articula violência contra as mulheres, racismo e patriarcado. O principal resultado da investigação aponta que a violência é uma das consequências da imbricação dos três sistemas de dominação-exploração, ou seja: patriarcado, racismo e capitalismo.
\end{abstract}

Palavras-chave: Patriarcado. Racismo. Capitalismo. Violência contra as mulheres.

VIOLENCE AGAINST WOMEN IN BRAZIL: a feminist, antiracist, and anticapitalist analysis

\begin{abstract}
This paper analyzes some of the results of the research program "The foundations of violence against women in Brazil", which investigates the origin and structure of this. In 2020, a documentary analysis based on the "Atlas of Violence 2020", in the "Yearbook of Public Security 2020" and in the "Gender statistics social indicators of women in Brazil (IBGE-2018)" document, to collect data referring to situations of violence against women. After this summing up, a review of the empirical literature, that is, reinterprets the data from a theoretical debate that connects violence against women, racism, and patriarchy. The main result points out that violence is one of the consequences of the overlapping of the three systems of domination-exploitation, namely: patriarchy, racism, and capitalism.
\end{abstract}

Keywords: Patriarchy. Racism. Capitalism. Violence against women

Artigo recebido em: 15/04/2021 Aprovado em: 20/11/2021

DOI: http://dx.doi.org/10.18764/2178-2865.v25n2p547-564

\footnotetext{
1 Doutora em Serviço Social. Professora Adjunta da Escola de Serviço Social da Universidade Federal do Estado do Rio de Janeiro - UNIRIO. E-mail: renata.costa@unirio.br

2 Graduanda em Serviço Social na Escola de Serviço Social da Universidade Federal do Estado do Rio de Janeiro - UNIRIO. Email:marianapaz@edu.unirio.br

${ }^{3}$ Graduanda em Serviço Social na Escola de Serviço Social da Universidade Federal do Estado do Rio de Janeiro - UNIRIO.. Email: carolinarubano@edu.unirio.br
} 


\section{INTRODUÇÃO}

$\mathrm{O}$ presente artigo analisa e debate alguns dos resultados do projeto de pesquisa "Os fundamentos da violência contra as mulheres no Brasil". O projeto é implementado, desde 2019, na Universidade Federal do Estado do Rio de Janeiro (UNIRIO) e investiga os elementos econômicos e sociais que originam e estruturam a violência contra as mulheres na realidade brasileira.

No aspecto metodológico, a pesquisa é realizada por meio de uma investigação e análise documental nas principais estatísticas nacionais sobre a violência contra as mulheres. Os dados são colhidos e sistematizados a partir de um referencial bibliográfico que articula violência, patriarcado, racismo e capitalismo.

No ano de 2020, o projeto foi executado a partir de duas estratégias: 1) análise dos dados do Anuário brasileiro de Segurança Pública 2020; do Atlas da violência 2020; e dodocumento "Estatísticas de gênero indicadores sociais das mulheres no Brasil (IBGE-2018); 2) articulação dos dados com a pesquisa bibliográfica sobre violência, racismo e patriarcado. 0 referencial teórico da pesquisa se fundamentou, principalmente, nos trabalhos de: Guerda Lener (2019), Paola Tabet (2014), Heleieth Saffioti (1985; 1987; 1988; 1993; 1994; 2000; 2015), Helena Hirata (2002; 2001; 2009; 2011; 2018) e Lélia Gonzalez $(2010 ; 2018)$.

Os dados usados na pesquisa são de relatórios nacionais já compilados. Nosso percurso metodológico foi selecionar os principais resultados estatísticos sobre a violência contra as mulheres e realizar um tratamento teórico dessa realidade expressa nos dados, ou seja, uma revisão da literatura empírica.

A violência contra as mulheres é consequência da estrutura patriarcal e racista, fruto de uma organização em sociedade fundamentada em desigualdades socioeconômicas entre homens, mulheres, brancos e negros. No Brasil, a visão convencional (senso comum) sobre o tema trata a violência contra as mulheres como consequência de um mau comportamento por parte das mulheres, que fere algumas regras sociais e familiares em relação aos papéis de gênero impostos em uma sociedade estruturada pelo patriarcado.

Ao longo de várias décadas, principalmente a partir dos anos de 1960, o fenômeno da violência como sinônimo de problemas entre o casal ou entre a família foi questionado tanto pelo movimento feminista como por intelectuais e pesquisadoras nas universidades. Este processo resultou em algumas conquistas jurídicas, de acesso a direitos, às políticas sociais e em um amplo arcabouço teórico 
que define, caracteriza e denuncia a violência como um fenômeno, social, público e de responsabilidade do Estado, no que se refere ao seu enfrentamento.

Em relação às conquistas sociais e jurídicas, temos como marcos: i) a criação da primeira delegacia de defesa da mulher na década de 1980; ii) a organização das políticas para as mulheres em 2003; iii)a promulgação da Lei Maria da Penha em 2006 (Lei 11.340/2006).

Um dos primeiros passos do movimento feminista e das estudiosas das relações de gênero/sexo foi conceituar a violência e suas expressões, deixando claro seu formato e impactos na vida das mulheres. Saffioti (1994) foi uma das teóricas que contribuiu com esse debate. A autora define a violência contra as mulheres como fruto de uma estrutura de poder. Logo, não é um fenômeno que se expressa pelos seguintes fatores: uma questão individual-privada; um consentimento e cumplicidade das mulheres; uma questão pertencente aos homens da classe trabalhadora; um comportamento mais atrelado aos homens negros, que são considerados mais violentos que os brancos.

A definição da autora desmonta alguns dos mitos em relação à violência contra as mulheres no Brasil. Saffioti (1994) destaca que esta violência se expressa de diferentes formas, a saber: ironia; espancamento; reprodução forçada; estupro; homicídios. A autora também analisa a responsabilidade do Estado no que se refere ao enfrentamento e a prevenção à violência, pois considera que este "[...] tem ratificado um ordenamento social de gênero através de um conjunto de leis que se pretendem objetivas e neutras, porque partem da errônea premissa de que a desigualdade de fato entre homens e mulheres não existe na sociedade" (SAFFIOTI, 1994, p.445).

As conquistas do movimento feminista e as pesquisas na área de gênero/sexo, raça/etnia e da violência possibilitaram o enfrentamento da naturalização da violência e a responsabilização do Estado. Este processo é perpassado porcontradições, ou seja, com avanços, recuos, limites e possibilidades no que se refere à análise e ao enfrentamento do fenômeno. No próximo tópico abordaremos os principais dados colhidos na execução do projeto de pesquisa, a partir de um debate teórico entre violência, patriarcado, racismo e capitalismo. 


\section{OS FUNDAMENTOS DA VIOLÊNCIA CONTRA AS MULHERES NO BRASIL}

De acordo com Saffioti (1994), a violência contra as mulheres é um fenômeno transversal à sociedade que integra a organização social de gênero no Brasil. É um elemento fundamental no processo de controle social e enquadramento das mulheres no ordenamento social de gênero.

O local privilegiado de exercício deste controle e reafirmação do poder dos homens sobre as mulheres é o domicílio. Dessa maneira, a violência contra as mulheres é uma violência de gênero, familiar e/ou domiciliar. Ese manifesta em física, sexual, psicológica e patrimonial.

No que se refere à transversalidade da violência contra as mulheres, como afirma a autora, esta ignora as fronteiras de classe social e de raça/etnia. Contudo, a vivência da violência e as possibilidades de ações e acesso aos recursos para seu enfrentamento são diferentes quando consideramos mulheres brancas ricas e de classe média, em relação às mulheres pobres e trabalhadoras, brancas e negras.

Dessa maneira, a violência é consequência de uma sociedade estruturada por relações patriarcais e racistas. Saffioti (2000) afirma que o patriarcado foi forjado, desde as primeiras sociedades, como sistema de dominação-exploração das mulheres e tem como fundamento a divisão sexual do trabalho.

Ao longo da história (sociedades primitivas, sociedades antigas, modo de produção feudal) 0 trabalho foi organizado de maneira social e sexual. Sendo assim, "a divisão sexual do trabalho está na base da subordinação da mulher ao homem, relação de dominação esta que coloca o fenômeno da reprodução como subordinado da produção" (SAFFIOTI, 1985, p.98). Essa lógica de divisão do trabalho, a partir do sexo, não foi superada em nenhuma sociedade anterior e nem no modo de produção capitalista. Pelo contrário, o capitalismo, em todos os países que se desenvolveu, desde o século XVIII na Inglaterra, estruturou os postos de trabalho, as relações de trabalho e os padrões salariais de forma desigual entre homens e mulheres.

Essa análise se articula com os resultados de pesquisa da antropóloga Paola Tabet (2014) que investigou a organização da atividade trabalho entre homens e mulheres nas sociedades de coleta, caça, pesca, agricultura e indústria. Os resultados de Tabet (2014) demonstram que o trabalho foi organizado, nesses diferentes momentos históricos, por meio de uma repartição desigual dos instrumentos, dos produtos do trabalho e do tempo de descanso quando consideramos homens e mulheres. A regra geral é: 
[...] a existência de uma diferença seja qualitativa, seja quantitativa, dos instrumentos à disposição de cada um dos sexos e mais exatamente de uma generalizada situação de subequipamento das mulheres e da existência de um gap tecnológico entre homens e mulheres no quadro das sociedades de caça e coleta, gap este que, com a evolução técnica, ampliou-se progressivamente e subsiste até hoje nas sociedades industrializadas (TABET, 2014, p. 109).

Tabet (2014) explica que nas sociedades primitivas, as divisões entre homens e mulheres foram baseadas nas diferenças biológicas, considerando o formato dos corpos e a procriação. Contudo, essas diferenças se tornaram sociais e se transformaram em hierarquias e acesso desigual das mulheres aos materiais e instrumentos de trabalho. Estas foram extorquidas através de uma carga maior de trabalho, possuindo menos tempo livre e de repouso em relação aos homens. Quando outros instrumentos de trabalho eram criados, as mulheres tinham acesso aos instrumentos rudimentares e obsoletos.

As pesquisas atuais de Hirata (2002; 2001; 2009; 2011; 2016) demonstram a permanência no modo de produção capitalista, desta lógica desigualde acesso ao trabalhoentre mulheres e homens, no que se refere às atividades, às tecnologias e aos salários. Ou seja, mesmo a divisão sexual do trabalho tendo configurações particulares a depender do período histórico e modo de produção que analisamos (sociedades primitivas; sociedades antigas; modo de produção feudal; modo de produção escravistas nas Américas; modo de produção capitalista), sua definição geral é a mesma, isto é, repartição desigual e hierárquica dos instrumentos, materiais e técnicas de trabalho e do tempo de repouso. Como afirma Hirata (2002, p.217) "[...] as formas da divisão sexual do trabalho podem mudar. A divisão sexual do trabalho permanece" (HIRATA, 2002, p. 217).

Hirata $(2002 ; 2001 ; 2009 ; 2011 ; 2016)$ demonstra que nos anos de 1990 houve um crescimento mundial do trabalho assalariado para as mulheres, seja no setor formal, informal e/ou de serviços. Contudo, este crescimento esteve associado à precarização e às péssimas relações e condições de trabalho para as mulheres que se expressam em: atividades de trabalho mal remuneradas e pouco valorizadas socialmente; promoções de carreira e direitos trabalhistas escassos ou nulos. Em termos gerais, temos o seguinte quadro: "[...] a despeito do melhor desempenho escolar das mulheres em relação aos homens em quase todos os países industrializados, a situação de inferioridade das mulheres no mercado de trabalho permanece" (HIRATA, 2016, p.5).

A autora demonstra que no capitalismo temos uma apropriação masculina da tecnologia. A cada nova tecnologia nos ramos industriais, por exemplo, as tarefas antes consideradas masculinas, ao se tornarem obsoletas pelos processos de inovação, passam a ser femininas. Um dos exemplos citados por Hirata (2002) é o caso da introdução de prensas automáticas nas oficinas gráficas. A prensa anterior, que era considerada atividade masculina, passa a ser um trabalho de mulher. Isso demonstra que as inovações 
técnicas são vividas, nos postos de trabalho, desigualmente, quando avaliamos homens e mulheres. As mulheres são consideradas incompetentes tecnicamente e não têm acesso aos novos postos qualificados de trabalho.

Dessa maneira, no capitalismo, de forma geral, o trabalho continua divido sexualmente, porém inaugurando uma nossa fase da divisão sexual do trabalho que apresenta dois fatores para as mulheres: 1) o trabalho assalariado conjugado com desvalorização social e salarial da força de trabalho das mulheres; 2) o trabalho doméstico (remunerado e não-remunerado).

Nessa nova fase da divisão sexual do trabalho, sob o capitalismo, Kergoat (2000) apresenta seus dois princípios organizadores: 0 da separação (existem trabalhos de homens e trabalhos de mulheres); o da hierarquização (um trabalho de homem "vale" mais do que um trabalho de mulher).

Diante disso, podemos concluir que, mundialmente, o modo de produção capitalista se originou e se desenvolveu mantendo a divisão sexual do trabalho, já existente em outros momentos históricos. Seu diferencial foi criar umafase para este fenômeno histórico-econômico.

Dado que a divisão sexual do trabalho é um permanente histórico nas diferentes sociedades e modos de produção, sua sustentação, na materialidade econômico-social, requer a criação de um sistema de dominação-exploração que implemente a desigualdade entre homens e mulheres. É necessário um aparato legal, social e cultural que opere como uma forma de dominação e exploração. O fenômeno decorrente da divisão sexual do trabalho e que funciona como vetor de dominação-exploração é denominado por autoras como Saffioti (1985) e Lerner (2019) de patriarcado.

Lener (2019) pesquisou historicamente sobre a origem e o desenvolvimento do processo de dominação sobre as mulheres, a fim de traçar subsídios teóricos que nos auxiliam: a entender como as diferentes sociedades desenvolveram a divisão sexual do trabalho; como criamos hierarquias, desigualdades e violência a partir do sexo; como na sociedade atual isso se tornou, também, um elemento estrutural e fundamento material da violência contra as mulheres.

Para Lerner (2019), o patriarcado não foi um evento pontual, não é um fenômeno arcaico e nem se limita a uma definição de poder do pai, presente em sociedades agrárias. É, na verdade, um sistema histórico que surgiu com o Estado arcaico, tendo como unidade básica a família patriarcal, ou seja, "[...] que se desenrolou durante um espaço de tempo de quase 2.500 anos, de cerca de 3100 a 600 a.C. Aconteceu, mesmo no Antigo Oriente Próximo, em ritmo e momento diferentes, em sociedades distintas (LENER, 2019, p.32-33). 
Lerner (2019) demonstra que durante o segundo milênio a.C. a formação das classes sociais para as mulheres conjugava indissociadamente o status econômico com a servidão sexual, mostrando que, desde 0 início, a posição de classe das mulheres foi determinada de maneira desigual, levando em consideração a servidão sexual.

Esse sistema de dominação-exploração que Lerner (2019) e Saffioti (2000;2015) denominam de patriarcado e expressa a dominação dos homens sobre as dimensões da vida das mulheres (produção, reprodução, sexualidade, socialização), foi criado pela divisão sexual do trabalho que fez do sexo um instrumento de dominação e exploração.

As consequências de uma realidade estruturada pela divisão sexual do trabalho e pelo patriarcado são desigualdades, hierarquias e opressões para as mulheres. Assim, a violência não é uma particularidade do modo de produção capitalista. Mas uma consequência de sociedades e modos de produção que se fundamenta na divisão sexual e no patriarcado.

A histórica do modo de produção capitalista nas diferentes regiões e países mostra que este não se desenvolveu sem a divisão sexual do trabalho e o patriarcado. Porém, países como o Brasil, que vivenciou o modo de produção escravista e deste transitou para o capitalismo, promovem uma divisão do trabalho que além de sexual, também é racial, pois utilizam a cor/raça/etnia para organizar o modo de produção, sua força de trabalho, seus padrões salariais e as condições de vida dos sujeitos.

Ao considerar esses mecanismos do modo de produção capitalista, Saffioti (2000) desenvolveu a ideia do nó formado pelo patriarcado-racismo-capitalismo que é o fundamento teórico de suas análises sobre violência contra as mulheres e a inserção das mulheres no mercado de trabalho.

De acordo com a autora, o nó patriarcado-racismo-capitalismo foi constituído nos séculos XVIXVIII. "[...] historicamente, o patriarcado é o mais antigo sistema de dominação-exploração. Posteriormente, aparece o racismo, quando certos povos se lançam na conquista de outros, menos preparados para a guerra" (SAFFIOTI, 1987, p.60). No caso do patriarcado, por exemplo, considera que é "[...] o elemento constante [...], ao qual foram se agregando sucessivamente diferentes modalidades de organização da produção: escravista, feudal e capitalista" (SAFFIOTI, 1985, p.101). Em síntese:

Desta sorte, não foi o capitalismo, sistema de dominação-exploração muitíssimo mais jovem que os outros dois, que 'inventou' o patriarcado e o racismo. Para não recuar demasiadamente na história, estes já existiam na Grécia e na Roma antigas, sociedades nas quais se fundiram com 0 sistema escravocrata. Da mesma maneira, também se fundiram com o sistema feudal. Com a emergência do capitalismo, houve a simbiose, a fusão, entre os três sistemas de dominaçãoexploração, acima analisados separadamente. Só mesmo para tentar tornar mais fácil a compreensão deste fenômeno, podem-se separar estes três sistemas. Na realidade concreta, eles são inseparáveis, pois se transformaram, através deste processo simbiótico, em um único 
sistema de dominação-exploração, aqui denominado patriarcado-racismo-capitalismo" (SAFFIOTI, 1987, p.60).

O nó de Heleieth Saffioti é a transposição para a teoria do que temos na realidade. O Brasil organiza o trabalho, desde o período colonial, usando da divisão sexual e racial para separar e hierarquizar os sujeitos nas diferentes atividades. Com o capitalismo, o recurso da divisão sexual e racial do trabalho foi acionado como um elemento fundamental para a origem e desenvolvimento de um modo de produção que tem na acumulação de capital seu princípio e que busca mecanismos e estratégias de exploração da força de trabalho para implementar seus objetivos econômicos. Dessa maneira,

[...] a simbiose patriarcado-racismo-capitalismo, entretanto, a meta da maximização do lucro é mediada pela supremacia masculina. E é desta forma que, pela via da subordinação da mulher ao homem e pela alocação prioritária da mulher aos aparelhos de reprodução, 0 patriarcadocapitalismo garante, simultaneamente, a reprodução da família trabalhadora e explora em grau mais intenso a força de trabalho feminina, quando dela necessita e nas proporções em que dela precisa (SAFFIOTI, 1985, p.138).

De acordo com Gonzalez (2018), temos uma divisão racial do trabalho que é a base dos critérios usados para determinar a posição dos sujeitos na estrutura de classes sociais. Em outra produção, Gonzalez (1984) afirma que o racismo é a ciência da superioridade eurocristã, branca e patriarcal. É um fenômeno materializado na discriminação racial, na segregação racial, na divisão espacial no mercado de trabalho, nos serviços públicos, no acesso aos direitos civis, políticos e sociais. É, assim, fruto da forma como construímos nossa história e as relações econômicas, sociais, políticas e culturais no Brasil.

Se o capitalismo, no Brasil, além de organizar o trabalho e a força de trabalho por meio da divisão sexual, o faz, também, a partir do critérioracial, origina o racismo como sistema de dominaçãoexploração. Dado que o critério racial foi acionado, no modo de produção escravista e no modo de produção capitalista, temos o fenômeno do racismo atravessando diferentes momentos da história do Brasil. O que irá diferenciar são as características e regras do racismo em cada momento históricoeconômico.

Dessa maneira, o racismo não é um fenômeno fruto de uma sociedade colonial e escravista, ou seja, uma herança histórica de um momento anterior que será extinto ao passo que o Brasil se desenvolve. $O$ racismo é um fenômeno que se reorganiza no modo de produção capitalista que, aqui no Brasil, organizou o trabalho e os sujeitos usando critérios raciais para hierarquizar com fins de acumulação de riqueza.

Para Moura (1983), o racismo funciona como mecanismo regulador do capitalismo dependente, com o objetivo de manter os baixos salários para essa massa marginal e da classe 
trabalhadora por abrangência. Dessa maneira, a divisão racial do trabalho, afirma Moura (1983, p.30), do sistema escravista, é acionada no contexto competitivo, pois:

[...] necessitava de um contingente de mão-de-obra marginalizado mais compacto e extenso do que o exército industrial de reserva no seu modelo clássico europeu. Havia necessidade da existência de uma grande franja marginal capaz de forçar a permanência dos baixos salários dos trabalhadores engajados no processo de trabalho. Essa franja foi ocupada, na sua esmagadora maioria, pelos negros, gerando isto uma contradição suplementar (MOURA, 1983, p.37).

O racismo e o patriarcado funcionam como critérios de distribuição das pessoas nas relações de produção e reprodução social. O resultado dessa imbricação entre um modo de produção (o capitalista) e fenômenos histórico-sociais (patriarcado e racismo), mas com função de dominação-exploração, por representarem um elemento estrutural que é a divisão sexual e racial do trabalho, resulta em: trabalhos de homens valem mais que trabalhos de mulheres; trabalhos de brancos(as) valem mais que trabalho de negros(as); trabalho de mulheres negras vale menos do que qualquer outro.

Dessa maneira, o patriarcado e o racismo são fenômenos históricos, que se imbricam com 0 modo de produção capitalista. Saffioti (1985; 1987; 1988; 1993; 2000; 2005) os define como três sistemas de dominação-exploração, não oscolocando no mesmo patamar e nem os analisando de maneira dualista, ou seja, patriarcado e racismo como dominação política e cultural e capitalismo como dominação econômica.

Como destacamos, a autora diferencia a natureza desses fenômenos (fatores históricos e modo de produção), mas isso não significa que patriarcado e racismo não operem na esfera econômica e só têm efeitos no âmbito cultural. Se assim fosse, não seriam os dois mecanismos fundamentais usados desde a origem do capitalismo, no Brasil, como fatores que estruturam e fundamentam este modo de produção, determinando condições de vida e trabalho desiguais e opressoras para as mulheres e a população negra. Safiotti (1987) deixa claro que:

Quando se usa um destes sistemas de dominação-exploração na forma substantiva e outro na forma adjetiva, como, por exemplo, na expressão capitalista patriarcal, está-se atribuindo maior importância ao capitalismo, deixando em plano secundário o patriarcado. 0 mesmo se passa com a expressão capitalismo racista. No primeiro caso, o patriarcado apenas qualifica o capitalismo, assim como no segundo o racismo exerce esta função de qualificação. Há também quem tome 0 patriarcado, o mais antigo sistema de dominação-exploração, e o qualifique com os sistemas de produção surgidos ao longo da história. Nesta linha de raciocínio, tem-se 0 patriarcado escravista, o patriarcado feudal e, finalmente, o patriarcado capitalista. Neste caso, privilegia-se 0 patriarcado, em prejuízo dos sistemas produtivos com os quais ele foi-se fundindo através dos tempos (SAFFIOTI, 1987, p.60-61).

Assim, patriarcado e racismo são os principais elementos acionados na organização e desenvolvimento do modo de produção capitalista para segmentar a força de trabalho. Isso se expressa 
quando analisamos os dados nacionais sobre as condições de vida e trabalho das mulheres em relação aos homens. Vejamos os gráficos abaixo construídos na pesquisa sobre as horas destinadas às atividades domésticas; os rendimentos médios das pessoas ocupadas; a proporção de pessoas nos trabalhos informais; a proporção de pessoas ocupadas no trabalho doméstico.

Gráfico 1- Número de horas semanais destinadas a atividades domésticas para pessoas de 14 anos ou mais de idade, por cor e sexo

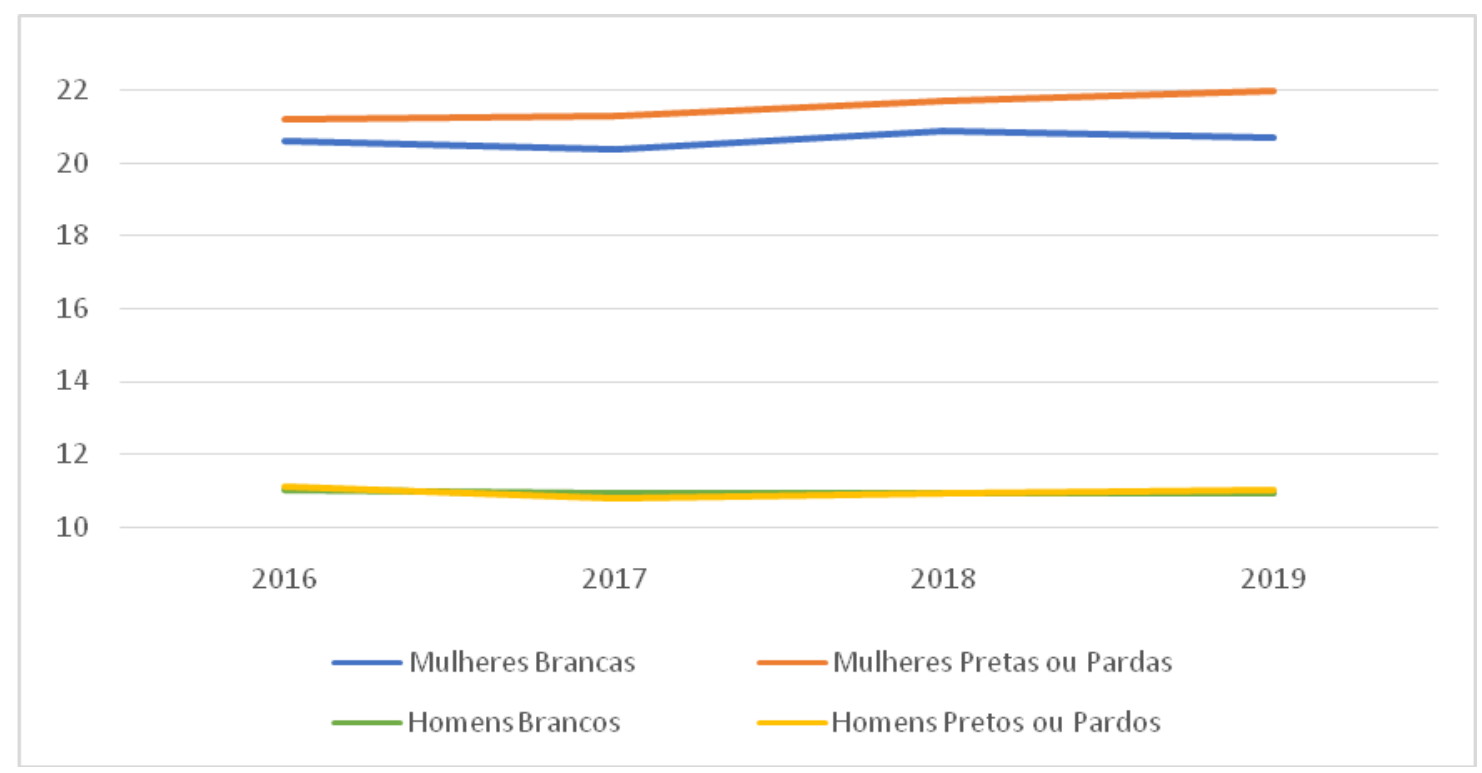

Fonte: Estatísticas de Gênero: Indicadores sociais das mulheres no Brasil (IBGE-PNAD Contínua).

Os dados demonstram que a cada uma hora de atividades domésticas realizada por homens, temos, aproximadamente, duas vezes a mais realizadas por mulheres, principalmente quando consideramos mulheres negras. Ou seja, entre homens e mulheres, no que se refere à realização das atividades domésticas em casa, é quase o dobro. Dessa forma, os afazeres domésticos, fundamentais para a reprodução da família e da força de trabalho, são, em sua maioria, realizados gratuitamente por mulheres.

O trabalho doméstico, no interior do domicílio, é imposto às mulheres e é a principal atividade de reprodução da mercadoria força de trabalho. 0 trabalho de reprodução biológica, alimentação, limpeza, cuidado com as crianças e doentes tem impacto nos custos da força de trabalho, pois se não fosse imposta como responsabilidade das mulheres poderia ser um custo para o capital. Assim, "[...] a concentração do trabalho reprodutivo na esfera doméstica pode permitir que o capital remunere a força de trabalho com um salário inferior ao que seria necessário caso todas essas condições essenciais à sobrevivência fossem compradas no mercado" (MATTOS, 2019, p.60). 
Gráfico 2- Rendimento médio real (a preços de 2019) de pessoas ocupadas com 14 anos ou mais por sexo e cor

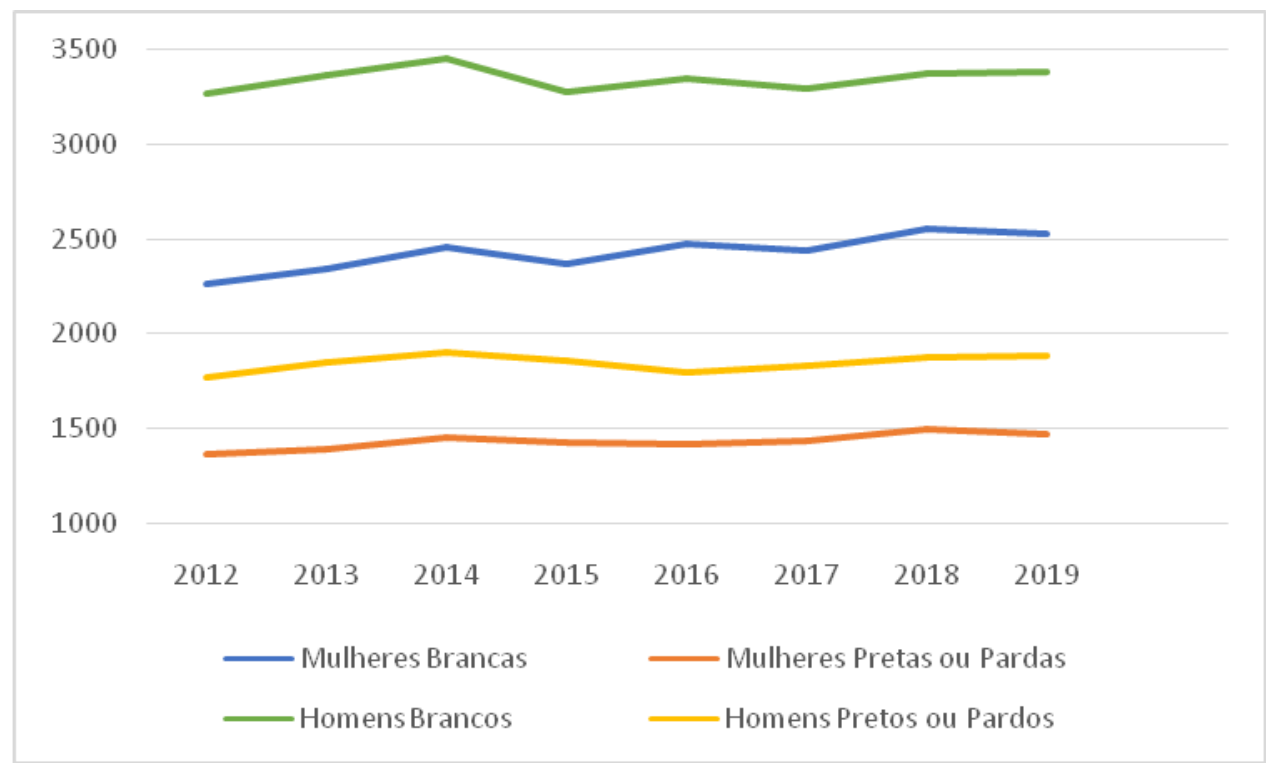

Fonte: Estatísticas de Gênero: Indicadores sociais das mulheres no Brasil (IBGE-PNAD Contínua).

Os dados demonstram que a base da estrutura salarial brasileira é determinada, de forma preponderante, por questões raciais. 0 quesito de gênero também estrutura, pois para uma dada cor/raça/etnia, as mulheres possuem menor rendimento médio em relação aos homens de todos os segmentos. Contudo, homens pretos e pardos recebem menos que mulheres brancas. Dessa maneira, a estruturante cor/raça/etnia concede melhores condições às mulheres brancas, por exemplo.Isso reflete 0 processo de formação e consolidação da classe trabalhadora e do trabalho assalariado no Brasil. Neste país, o modo de produção se origina e se desenvolve usando do racismo para implementar sua lógica de produção e reprodução.

Em relação aos trabalhos informais e as pessoas ocupadas no trabalho doméstico temos as seguintes estatísticas: 
Gráfico 3- Proporção de pessoas com 14 anos ou mais em trabalhos informais em relação ao total de pessoas ocupadas em atividades não agrícolas, por sexo e cor

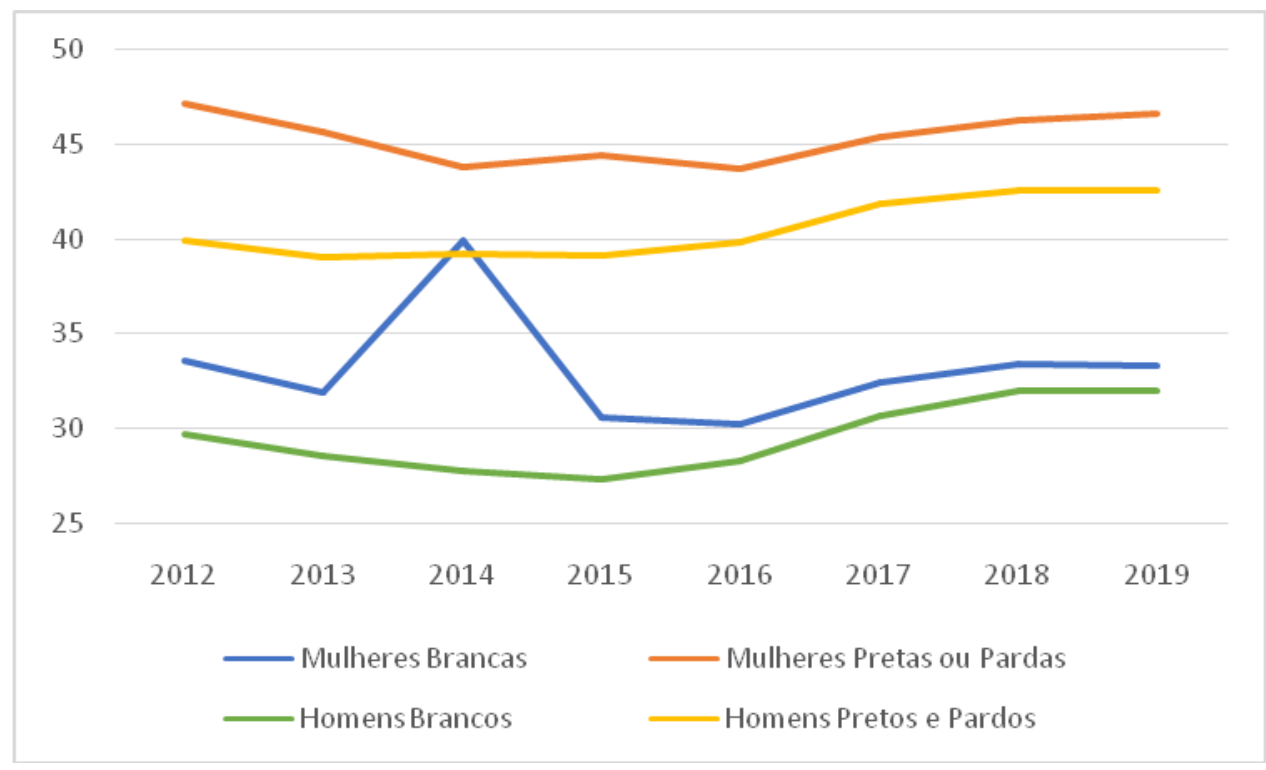

Fonte: Estatísticas de Gênero: Indicadores sociais das mulheres no Brasil (IBGE-PNAD Contínua).

Gráfico 4- Proporção de pessoas com 14 anos ou mais ocupadas em trabalho doméstico em relação ao total de pessoas ocupadas, por sexo e cor

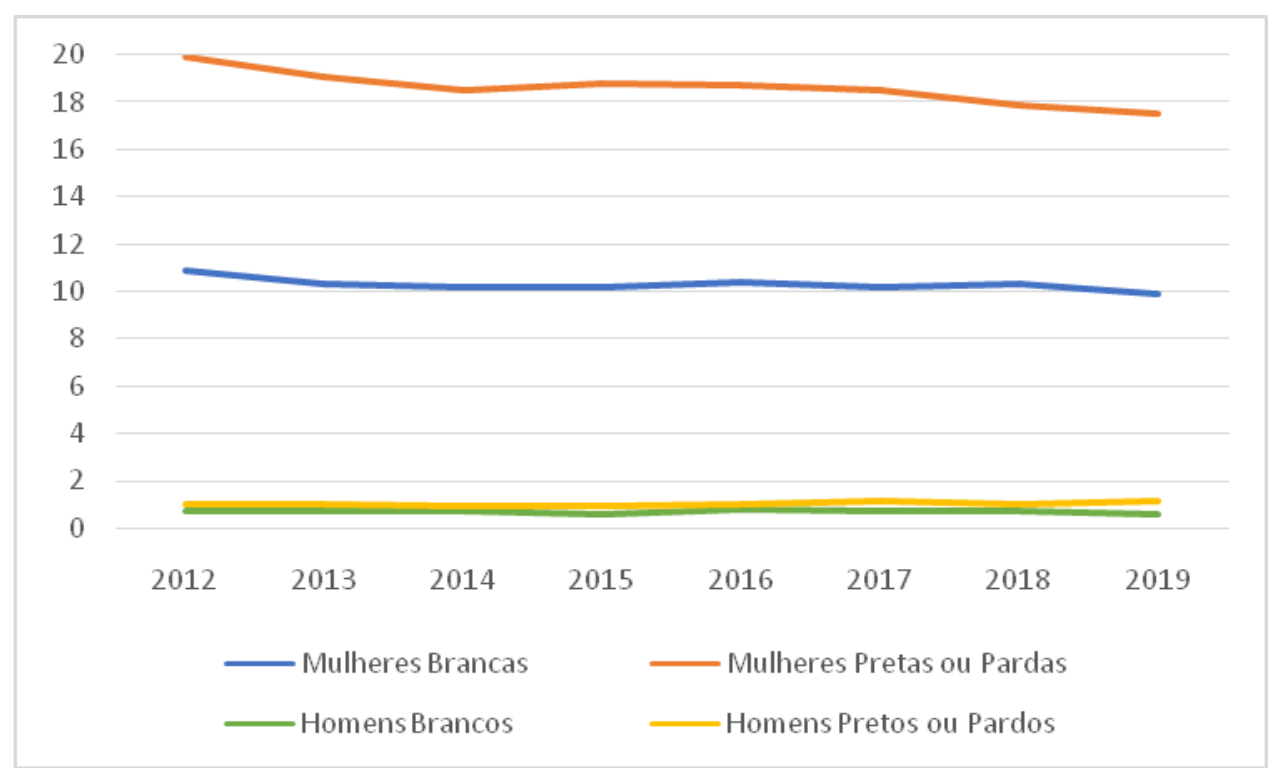

Fonte: Estatísticas de Gênero: Indicadores sociais das mulheres no Brasil (IBGE-PNAD Contínua).

No que se refere à ocupação no mercado e nas atividades de trabalho, se considerarmos a informalidade e a inserção no trabalho doméstico, como expresso nos gráficos 3 e 4, as mulheres negras estão no topo da pirâmide, ou seja, são as que mais estão no setor informal e a força de trabalho mais 
empregada no trabalho doméstico. Essa configuração de vida e de trabalho é o fundamento material para compreendermos as expressões da violência contra as mulheres e suas possibilidades de enfrentamento.

Quando Saffioti (1994) define a violência contra as mulheres como um controle social e um enquadramento das mulheres às relações patriarcais, e aqui incluiriamos racistas, está retratando que a violência é consequência de uma sociedade que impõe condições de vida e de trabalho, a partir de relações de gênero e étnicas-raciais desiguais, hierárquicas e opressoras. A violência é um mecanismo potente de imobilização dos sujeitos para se manterem nos destinos impostos pelas relações econômicas e sociais.

Como já sinalizamos, é um fenômeno que não atinge apenas as mulheres que vivenciam de forma mais agudizada essa lógica da divisão sexual e racial do trabalho, pois atinge as mulheres das diferentes classes. Contudo, os dados e estatísticas demonstram quais são as mais atingidas com a violência e como isto retrata as consequências de um modo de produção que inseriu as mulheres negras nas piores condições de vida e trabalho. 0 gráfico a seguir apresenta dados sobre os assassinatos de mulheres e as tabelas sobre feminicídio e tipos da violência.

Gráfico5 - Taxa de homicídio por 100 mil habitantes, do total de mulheres, de mulheres negras e de mulheres não negras. De 2008 a 2018.

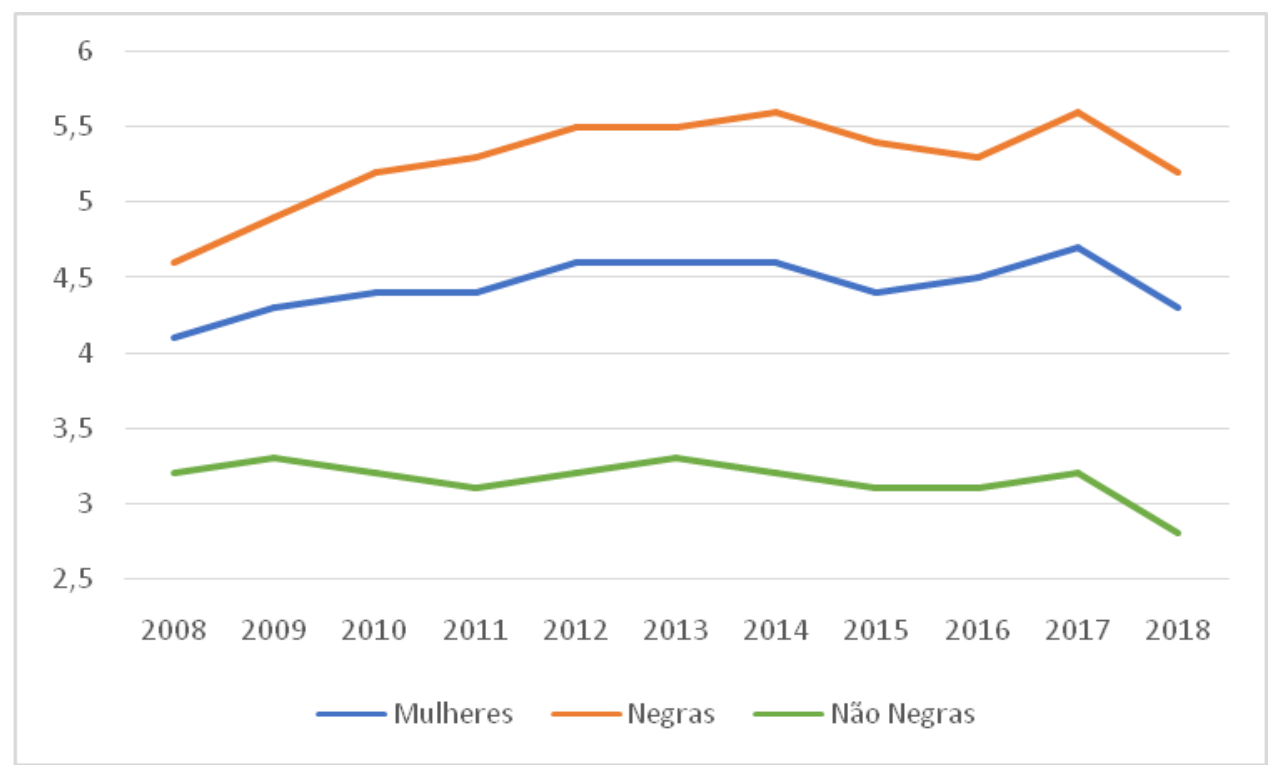

Fonte: SIM/MS. Retirado do Atlas da Violência 2020, publicado pelo IPEA.

De acordo como Atlas da Violência 2018, a cada duas horas uma mulher foi assinada no Brasil, contabilizando 4.519 vítimas. 0 gráfico 5 demonstra que nos últimos 11 anos, a taxa de homicídio das mulheres negrasficou entre 4.5 - 5.5 e taxa de homicídio das mulheres não negras entre 2.5-3.0, ou 
seja, ao destrincharmos os dados da violência pela cor, encontramos, entre 2008-2018, uma taxa de homicídio maior entre as mulheres negras.

Em relação aos dados de feminicídio temos a seguinte configuração:

Tabela 1 - Feminicídios em 2019 no Brasil por cor, vínculo e local

\begin{tabular}{|c|c|c|}
\hline \multirow{4}{*}{ Cor } & Negra & $66,6 \%$ \\
\cline { 2 - 3 } & Branca & $33,1 \%$ \\
\cline { 2 - 3 } & Amarela & $0,3 \%$ \\
\hline \multirow{4}{*}{$\begin{array}{c}\text { Relação entre vítima e autor } \\
\text { da violência }\end{array}$} & Companheiro/ex-companheiro & $89,9 \%$ \\
\cline { 2 - 3 } & Parente & $4,4 \%$ \\
\cline { 2 - 3 } & Conhecido/outro vínculo & $3,1 \%$ \\
\cline { 2 - 3 } & Desconhecido/sem vínculo & $2,6 \%$ \\
\hline \multirow{3}{*}{ Local do crime } & Residência & $58,9 \%$ \\
\cline { 2 - 3 } & Via pública & $25,4 \%$ \\
\cline { 2 - 3 } & Outros & $15,7 \%$ \\
\hline
\end{tabular}

Fonte: Anuário Brasileiro de Segurança Pública 2020.

Os dados demonstram que as mulheres negras são as mais vitimizadas pelo feminicídio. Em quase $90 \%$ dos casos, o autor da violência é o companheiro/ex-companheiro. 0 domicílio é ainda o local de grande incidência de morte de mulheres.

Esses dados expressam a amplitude das mortes de mulheres no Brasil. Ainda, a alta taxa de homicídio de mulheres é explicada, em sua maior parte, pela alta taxa referente a mulheres negras em relação às não negras. Isto, de alguma forma, confirma (ou, pelo menos, não contradiz) nossa análise, fundamentada em Saffioti (1994),de considerar o fenômeno da violência contra as mulheres como uma das consequências das relações sociais forjadas pelas relações patriarcais e racistas.

No que se refere ao tipo de violência praticada temos os seguintes dados:

Tabela 2 - Números absolutos de violência contra as mulheres por tipo

\begin{tabular}{|c|c|c|c|}
\hline & $\mathbf{2 0 1 8}$ & $\mathbf{2 0 1 9}$ & Variação (\%) \\
\hline Lesão corporal dolosa & 248.439 & 266.310 & $\mathbf{7 , 2}$ \\
\hline Ameaça & 444.056 & 498.597 & $\mathbf{1 2 , 2}$ \\
\hline Estupro e estupro de vulnerável & 55.811 & 55.499 & $\mathbf{- 0 , 5}$ \\
\hline Tentativa de estupro & 5.910 & 5.676 & $\mathbf{- 4 , 0}$ \\
\hline Assédio e importunação sexual & 5.556 & 12.604 & $\mathbf{1 2 6 , 8}$ \\
\hline
\end{tabular}

Fonte: Anuário Brasileiro de Segurança Pública 2020. 


\section{A VIOLÊNCIA CONTRA AS MULHERES NO BRASIL: uma análise feminista, antirracista e anticapitalista}

No caso de estupros, por exemplo, a edição de 2015 do Anuário contabilizou um estupro a cada 11 minutos. Na edição de 2020, a que analisamos, temos um estupro a cada oito minutos. Em 2019, por exemplo, o Brasil contabilizou um total de 66.123estupros, desses, 55.499 tiveram como vítimas somente mulheres. Se analisarmos os assédios e a importunação sexual, em 2019 houve um aumento de mais de $126 \%$ desses casos.

Diante do exposto, consideramos que uma das estratégias de análise da violência contra as mulheres é sua articulação com as condições socioeconômicas, com foco na inserção do mercado de trabalho, pois desvenda a base estrutural que explicita a lógica imposta às mulheres trabalhadoras, principalmente, as negras, na sociedade capitalista.

No capitalismo, a força de trabalho das mulheres sempre foi tratada como inferior, com baixas remunerações e piores condições e relações de trabalho. A consequência disso será um contexto perpassado por violência e opressões. Estes são um dos principais mecanismos de controle da classe trabalhadora para a manutenção da organização de classes no modo de produção.

A violência é um fenômeno que tem como base material a organização da produção e da reprodução, mas suas expressões não se limitam a isso. A potência do patriarcado, como sistema de dominação-exploração e que estrutura as relações de gênero, impõem uma realidade para todas as mulheres que é perpassada por sexismo, machismo e violência. O patriarcado atinge todas as mulheres, mas ele não age sozinho, pode até se expressar sozinho, a depender da classe social, mas sua origem e organização parte de um nó (patriarcado-racismo-capitalismo) que tem um sentido material para o processo de produção e reprodução do capitalismo. Por isso, nossa análise tem como foco os fundamentos da violência contra as mulheres e não, apenas, suas expressões.

Mattos (2019) afirma que as divisões no interior da classe trabalhadora são necessárias ao capitalista como maneira de rebaixar o custo médio da força de trabalho. Isto tem um papel na formação dos salários, pois cria uma fração da classe trabalhadora que ganha menos por ser mulher e/ou negra, ou negro, no caso da força de trabalho dos homens negros, o que contribui com a acumulação capitalista, por possibilitar a redução de custos com esse perfil da classe trabalhadora, que numericamente é maior no Brasil. Estas afirmações não visam uma análise economicista da violência contra as mulheres. Pelo contrário, demarcamos a amplitude desse fenômeno nas diferentes classes, no Brasil, mas decidimos focar em análises e explicações nos sujeitos que mais perdem no capitalismo, ou seja, as mulheres negras.

Dessa maneira, consideramos que a violência contra as mulheres é uma das principais consequências de um modo de produção que tem como fundamento a divisão sexual e racial do trabalho. 
O objetivo desta análise é, além de definir a violência e suas formas de manifestações, construir um caminho teórico que desvende seus fundamentos.

\section{CONCLUSÃO}

No Brasil, temos uma estrutura material que origina e fundamenta as desigualdades e hierarquias entre homens e mulheres. A divisão sexual e racial do trabalho é a base de explicação da subordinação das mulheres e sua consequência, o patriarcado e o racismo, os elementos histórico-sociais que determinam e caracterizam as relações de gênero e étnico-raciais. A nossa realidade não é fundamentada por relações de gênero e étnico-raciais diferentes, porém igualitárias, sem violência e opressões. Pelo contrário, são desiguais, violentas e hierárquicas.

A violência, de forma geral, é um elemento estrutural em um modo de produção, como 0 capitalista, que tem como fundamento exploração e alienação. As condições materiais de vida incidem na vivência da violência e no acesso às possibilidades de enfrentamento. Uma mulher negra e pobre, empregada no setor informal de trabalho e/ou no trabalho doméstico, com salários baixos e sem acesso a direitos sociais e trabalhista, terá condições diferentes em relação a uma mulher branca de classe média ou alta.

Dessa maneira, uma análise que visa apontar a origem e a estrutura da violência contra as mulheres no Brasil deve ir à raiz dessa violência. A pesquisa mostrou que sua raiz está atrelada à organização da produção e da reprodução do capitalismo que se desenvolve atrelado ao patriarcado e ao racismo.

Ao articularmos as expressões da violência contra as mulheres às configurações do mercado de trabalho, desvendamos sua base material. Assim, as estatísticas são manifestações de um cotidiano perpassado por elementos histórico-econômicos que se desenvolvem juntos e promovem desigualdades e hierarquias de classe, gênero/sexo e raça/etnia.

\section{REFERÊNCIAS}

FÓRUM BRASILEIRO DE SEGURANÇA PÚBLICA. Anuário Brasileiro de Segurança Pública 2020.

Disponível em: https://forumseguranca.org.br/anuario-brasileiro-seguranca-publical. Acesso em: 20 de nov. 2020.

GONZALEZ, Lélia. Racismo e sexismo na cultura Brasileira. Revista Ciências Sociais Hoje, Anpocs, 1984. Disponivel em: https://edisciplinas.usp.br/pluginfile.php/4584956/mod_resource/content/1/06\%20- 
\%20GONZALES\%2C\%20L\%C3\%A9lia\%20-

\%20Racismo_e_Sexismo_na_Cultura_Brasileira\%20\%281\%29.pdf. Acesso em: 06 jun. 2010.

GONZALEZ, Lélia. Primavera para as rosas negras: Lélia Gonzalez em primeira pessoa. Diáspora Africana: Editora Filhos da África, 2018.

HIRATA, HELENA. Globalização e divisão sexual do Trabalho. In: Cadernos Pagu. (17/18) 2001/02: pp.139-156.

HIRATA, Helena. Nova divisão sexual do trabalho? Um olhar voltado para a empresa e a sociedade. Boitempo, 2002.

HIRATA, Helena. A Precarização e a Divisão Internacional e Sexual do Trabalho. In: Sociologias. Porto Alegre, ano 11, $n^{0} 21$, jan.jjun. 2009, p. 24-41.

HIRATA, Helena. Tendências recentes da precarização social e do trabalho: Brasil, França, Japão.CADERNO CRH, Salvador, v. 24, n. spe 01, p. 15-22, 2011.

HIRATA, Helena. Mulheres brasileiras: relações de classe, de raça e de gênero no mundo do trabalho. In: Dossiê Brasil, potência em questão. N. 26. Revue franco-brésilienne de géographie / Revista francobrasilera de Geografia. 2016.

INSTITUTO DE PESQUISA ECONÔMICA APLICADA (IPEA). Atlas da violência 2020. Disponível em: https://www.ipea.gov.br/atlasviolencia/download/24/atlas-da-violencia-2020. Acesso em: 20 ago. 2020.

INSTITUTO BRASILEIRO DE GEOGRAFIA E ESTATÍSTICA - IBGE. Estatísticas de Gênero: Indicadores sociais das mulheres no Brasil. Notas técnicas. 2018. Disponivel em:

https://www.ibge.gov.br/estatisticas/multidominio/genero/20163-estatisticas-de-genero-indicadores-sociaisdas-mulheres-no-brasil.html?=\&t=o-que-e. Acesso em: 20 de junho de 2020.

KERGOAT, Danièle; HIRATA, Helena.Divisão Sexual do trabalho e relações sociais de sexo. In: DictionnaireCritiqueduféminisme. Ed. PressesUniversitairesde France. Paris, novembro de 2000.

LENER, Gerda. A criação do patriarcado: história da opressão das mulheres pelos homens. São Paulo: Cultrix, 2019.

MOURA, Clóvis. Brasil: raízes do protesto negro. São Paulo: Global, 1983.

MATTOS. Marcelo. Badaró. A classe trabalhadora: de Marx ao nosso tempo. 1. ed. São Paulo: Boitempo, 2019.

SAFFIOTI, Heleieth. Força de trabalho feminina no Brasil: no interior das cifras. Perspectivas, São Paulo, n. 8, 1985.

SAFFIOTI, Heleieth. O poder do macho. São Paulo: Moderna, 1987. 
SAFFIOTI, Heleieth. Movimentos sociais: face feminina. In Carvalho, Nanci Valadares de. (Org.) A condição feminina. São Paulo, Revista dos Tribunais Ltda., Edições Vértice, 1988.

SAFFIOTI, Heleieth. Diferença ou indiferença? Gênero, raça/etnia e classe social. In: ADORNO, Sergio (org.) A Sociologia entre a Modernidade e a Contemporaneidade. POA: PPGS/UFRGS, 1993.

SAFFIOTI, Heleieth. Violência de gênero no Brasil atual. In: Estudos Feministas. 443 N. E./1994.

SAFFIOTI, Heleieth. Quem tem medo dos esquemas patriarcais de pensamento? In: Crítica Marxista. São Paulo, Boitempo, v.1, n. 11, 2000, p. 71-75.

SAFFIOTI, Heleieth. Gênero, patriarcado, violência. 2. ed. São Paulo: Expressão Popular: Fundação Perseu Abramo, 2015.

TABET, Paola. Mãos, instrumentos, armas. In: FERREIRA, V. et al.0 patriarcado desvendado: teorias de três feministas materialistas: ColetteGuillaumin, Paola Tabet e Nicole Claude Mathieu. Recife: SOS Corpo, 2014. 